\title{
FEMINISMO E ESTADO: DESAFIANDO A DEMOCRACIA LIBERAL
}

\author{
Silvana Aparecida Mariano \\ Mestre em Sociologia Política pela UFSC
}

\section{Resumo}

Este artigo explora a trajetória do movimento feminista no Brasil abordando a mudança quanto à sua concepção de Estado e seus conflitos com a democracia liberal. O foco central de discussão é a contribuição das reivindicações feministas. embora não exclusivas, por colocar em debate as limitações dos regimes democráticos liberais, assentando com isso novos parâmetros para a democracia. Tal reordenamento é discutido a partir das demandas feministas por políticas públicas voltadas para a questão de gênero, em especial as ações afirmativas que visam compensar as desvantagens das mulheres.

Palavras-chave: feminismo; gênero; políticas públicas; democracia.

mbora o movimento feminista seja composto por várias verten-

tes possíveis de serem distinguidas empiricamente, cremos que de qualquer forma há uma base ideológica comum que nos permite falar teoricamente de feminismo, mas nem sempre de feminismos.

Analisando-se o feminismo brasileiro da década de 1970 até a atualidade, pode-se identificar uma trajetória de mudanças na relação entre o movimento e o Estado. Essa trajetória vai da negação do Estado, como espaço legítimo de participação, à busca de participação e/ou representação feminina no Estado (BLAY, 1999; PAOLI, 1995; PINTO, 1994; ALVAREZ, 2000b; 2000c). Num outro aspecto, a trajetória feminista vai da postura de defesa de direitos da democracia liberal à postura de questionamento do liberalismo como filosofia política orientadora da atuação do Estado (MIGUEL, 2000).

Essas mudanças podem ser apreendidas através do conteúdo das políticas públicas reivindicadas pelas feministas. Costuma-se dizer 
que as feministas, a partir da década de 80 , transformaram suas bandeiras de luta, antes voltadas primordialmente à esfera societária, em propostas de políticas públicas, tendo como alvo de reivindicações o Estado (BLAY, 1999). Tal reorientação política do movimento trouxe à tona o dilema institucionalização $\mathrm{x}$ autonomia, colocando-o no centro dos debates feministas.

Ao transformar as bandeiras de luta em propostas de políticas públicas, as feministas demandam do Estado a promoção de ações para eliminar as desigualdades de gênero, objetivando a equiidade entre homens e mulheres. Com isso, colocam em questão alguns princípios da democracia liberal, tais como a igualdade formal entre os indivíduos, mediante a universalização dos direitos que concebem o indivíduo como única unidade política, e a neutralidade das instituições públicas.

A incorporação de tais demandas pelo Estado é vista, na perspectiva feminista, como condição para a ampliação da democracia (COSTA, 1997; BLAY, 1999). Nesse sentido, abordaremos suas razões que justificam considerar a importância do Estado, o que vem fundamentar a interlocução com instâncias estatais de poder.

O fato de privilegiar a ação junto ao Estado e instâncias de poder provocou uma reformulação nas estratégias e formas de organização do movimento feminista. Assim, será também abordada a importância das ONGs - organizações não-governamentais - e das redes feministas para a articulação de suas demandas e o crescimento dessas redes diante do contexto de globalização.

\section{Feminismo, Estado e democracia}

A formação no novo feminismo é marcada após 1960 em alguns países da Europa e nos Estados Unidos e se fez presente no Brasil sobretudo no período após 1975. Por feminismo estamos entendendo

“(...) um conjunto de idéias, críticas e objetivos fundados sobre a noção de que as mulheres constituem uma categoria especial de pessoas com certas características e experiências em comum, tais como a gestação e educação dos filhos, quer estas 
sejam enraizadas na biologia, quer sejam na cultura (FERREE, HESS apud MOGHADAM, 2000). Uma outra premissa essencial é de que as mulheres têm uma posição de desvantagem no que é com efeito um mundo do homem. Esta desvantagem é manifestada nas instituições familiar, econômica, política e cultural e ela pode ser diferenciada ou exacerbada pela era histórica ou sistema econômico ou político. O feminismo oferece uma forma de análise e uma crítica das posições das mulheres e da sociedade como um todo e um objetivo para efetuar uma mudança social através de melhorias no status legal e posições sociais das mulheres. Os objetivos de igualdade, autonomia, empoderamento ou transformação social podem ser enfatizados e priorizados diferentemente por organizações de mulheres, estando sujeitos a contextos políticos e econômicos" (MOGHADAM, 2000, p. 60)'.

Em sua origem, o movimento feminista advogava uma noção de autonomia que representava o estar "de costas" para o Estado. Tal postura se justificava, seja pela necessidade de afirmação da identidade própria do feminismo, seja pela importância da negação das formas autoritárias de poder refletidas no Estado (PAOLI, 1995). No caso brasileiro e no da América Latina isso era ainda mais patente em face da conjuntura política do regime militar.

As mudanças na postura do movimento de mulheres, quanto a relacionar-se ou não com o Estado, estão, muitas vezes, relacionadas com o perfil político dos governos. Assim, a ausência de uma distinção entre Estado e Governo pode confundir o debate sobre a reorientação política do movimento de mulheres.

Tratando-se do Brasil, no processo de restauração democrática, em especial a partir de 1982, algumas reivindicações feministas foram institucionalizadas pelos governos, seja em razão do interesse de inserção por parte das ativistas, seja em razão dos interesses políticos de partidos políticos e governos com o fim de capitalizar tais demandas (ALVAREZ, 1988 e BLAY, 1999).

Transformar bandeiras feministas em propostas para políticas públicas demandava a participação de quadros do movimento feminis-

1 Tradução realizada pela autora. 
ta nos aparelhos de Estado (SCHUMAHER; VARGAS, 1994: JELIN, 1994 e BLAY, 1999). Isso representa uma nova abordagem sobre a importância do Estado como interlocutor e sobre a autonomia do movimento. Passa-se a entender que

“(...) os anseios por mais espaços democráticos gestam-se no interior da sociedade através dos movimentos sociais, mas não se esgotam aí. Para que suas reivindicações e propostas transcendam a discussão interna e tenham efeitos concretos na vida da sociedade, devem passar em algum momento pelo campo político como propostas partidárias, políticas públicas, ajustes institucionais, etc." (PINTO, 1994, p.259)².

Para a autora, o posicionamento de defesa de autonomia dos movimentos em geral, e das feministas em particular, como ausência de relação com o Estado favorecia a reprodução da privatização do público, com um Estado defensor de supostos interesses gerais sem ancoragem nos interesses dispersos na sociedade. O despertar para a necessidade de se inserir nesse campo político institucionalizado, que ocorreu por parte de uma corrente do feminismo desde a década de 80 , reflete uma concepção de que os movimentos sociais não prescindem do Estado, conforme defendido por Sérgio Costa (1994).

Na avaliação de Céli Pinto (1994, p.270), a penetração do movimento feminista no Estado, assim como dos movimentos sociais em geral, resultaria, sem dúvida, “em perda de um grau de autonomia e em uma real ameaça de perda de identidade". Contudo esse é um risco necessário como alternativa para o também necessário alargamento dos campos de ação dos movimentos, visando assim potencializar seus resultados, bem como ampliar a agenda do campo político institucional.

Nessa perspectiva, as propostas de políticas públicas devem ser forjadas nos movimentos ou na sociedade civil, portanto fora do Estado, engendrando assim um caráter democratizador do campo político institucional com demandas que se formam de fora para dentro do Estado. Isso não significa dizer que a ação política dos movimentos e

\footnotetext{
2 A autora se refere à possibilidade de as reivindicações e propostas forjadas nos movimentos serem incorporadas na agenda pública e jamais à possibilidade de os movimentos tornarem-se partidos políticos.
} 
da sociedade civil se esgote no âmbito do Estado. Trata-se de uma abordagem que, mesmo reconhecendo a dimensão descentrada do poder e da política, ainda interpreta como importante o campo institucional, como forma para buscar maior universalidade das mudanças pretendidas ou como forma de democratizar o Estado. Para os movimentos sociais o Estado se torna, nessa concepção, interlocutor privilegiado, pois

"(...) devemos ver a política como algo mais que um conjunto de atividades específicas que ocorrem em espaços institucionais claramente delimitados, tais como parlamentos e partidos; ela deve ser vista como abrangendo também lutas de poder realizadas em uma ampla gama de espaços culturalmente definidos como privados, sociais, econômicos, culturais e assim por diante. (...) No entanto, uma concepção descentrada do poder e da política não deve desviar nossa atenção do modo como os movimentos sociais interagem com a sociedade política e o Estado e 'não deve nos levar a ignorar a maneira como o poder se sedimenta e se concentra em instituições e agentes sociais" (CANCLINI, 1988, apud ALVAREZ; DAGNINO; ESCOBAR, 2000, p.30).

Os novos movimentos sociais deram visibilidade ao fato de que a ação política não é restrita à esfera estatal, aos partidos e aos sindicatos. As feministas foram ainda mais longe advogando a idéia de que "o pessoal também é político". Com isso, ampliaram a noção de campo político e questionaram a separação da esfera pública e da privada, pretendendo assim uma osmose entre elas e, portanto, entre as esferas masculina e feminina (BUTTAFUOCO, 1995).

A ação política passou então a ser valorizada em diversos domínios sociais, extrapolando os limites estatais e institucionalizados. A esfera pública tornou-se mais ampla em relação à versão tradicional, incorporando questões antes relegadas à esfera privada e/ou ao mercado. Temáticas antes destinadas à privacidade tornaram-se alvo de politização na esfera pública, como, por exemplo, a maternidade, os direitos reprodutivos e a violência contra a mulher. Contudo, isso não significa o fim da esfera privada, mas seu questionamento e sua redefinição.

Com a noção ampliada de esfera pública e de ação política, os próprios termos conceituais da igualdade e da desigualdade passam 
por uma reelaboração no interior dos movimentos, que constroem também um outro par conceitual entre o direito à igualdade e o direito à diferença.

Em função dessa ampliação, é possível que algumas abordagens interpretem a relação dos movimentos com o Estado como um estreitamento da esfera pública. Neste trabalho não tratamos desta abordagem, nem as/os autoras/es aqui exploradas/os partem de tal interpretação. Ao contrário, a proposta destas/es autoras/es vem acompanhada da ênfase na necessidade de preservação do movimento feminista em arenas exteriores ao Estado. Esta abordagem concebe o movimento feminista em duas frentes: uma esfera societária, que objetiva mudanças nos padrões de comportamento sexista; e uma esfera estatal, que demanda mudanças no sistema político como forma de atingir mais amplamente toda a sociedade. O próprio sucesso dos instrumentos estatais criados está, nessa perspectiva, relacionado à representatividade política do movimento feminista no seio da sociedade, com condições assim de fazer pressão de fora do Estado (BLAY, 1999; PINTO, 1994 e ALVAREZ, 1988).

Nesse sentido, damos importância central ao Estado para a análise da ampliação da democracia, mesmo reconhecendo que esta não se esgota no âmbito estatal. Em publicação do Instituto Brasileiro de Administração Municipal - IBAM -, intitulada Democratização dos poderes municipais e a questão de gênero, são apontadas três razões básicas para considerar tal importância. Primeiro, pela própria centralidade do Estado em termos de poder político;

“(...) afinal, embora se reconheça atualmente que o poder político não se esgota no âmbito do Estado e que está presente em todas as relações sociais, não se nega que este continua sendo arena privilegiada para o seu exercício" (COSTA, 1997, p.22).

Segundo,

“(...) pela importância das políticas públicas na expansão dos direitos da cidadania aos segmentos sociais marginalizados, excluídos ou desigualmente tratados, entre os quais, em geral, se incluem as mulheres" (COSTA, 1997, p.23). 
Terceiro, por julgar-se importante democratizar o Estado e, assim, democratizar as políticas, entendendo-se que

"(...) as políticas englobam um conjunto de processos mediante os quais as demandas sociais se transformam em opções políticas e em tema de decisão das autoridades públicas" (COSTA, 1997, p.24).

Pode-se dizer que esta terceira é resultante das duas primeiras.

\section{Gênero e políticas públicas: desafios à democracia liberal}

Ao se inserirem no campo político institucional e demandarem a incorporação de suas bandeiras nas políticas públicas, as feministas se colocam em debate com a teoria política liberal. Pode-se dizer que, numa primeira fase, a orientação do movimento ia no sentido de reivindicar determinadas igualdades, até mesmo jurídicas, entre homens e mulheres, ficando assim nos limites da proposta liberal. Pode-se dizer que

"(...) durante muito tempo, a luta das minorias - termo que incluiu também as mulheres, já que se refere a uma inferioridade social e política, não numérica - foi pelo acesso aos direitos individuais prometidos pelo liberalismo e pela democracia. (...) Os princípios do liberalismo não eram colocados em questão: o que se criticava era sua insuficiente aplicação prática e a exclusão de segmentos da sociedade, como mulheres, negros, índios, etc." (MIGUEL, 2000, p.94) grifo do autor).

Nos anos 90, há uma mudança de atitude por parte do movimento feminista que revela o rápido desencanto com a prática política institucional. Tal desencanto se reflete numa tentativa de repensar os princípios da democracia liberal. Assim,

" $($... $)$ uma fecunda corrente da teoria política, vinculada ao feminismo, busca demonstrar que um viés sexista contamina os conceitos da democracia a partir de sua origem e que é necessária uma ruptura radical com as tradições anteriores de pensamento. De maneira mais prática, os mecanismos de ação afirmativa são a 
demonstração de que a mera igualdade formal é insuficiente; que ela perpetua, recobre e, em última análise, legitima a desigualdade substantiva" (MIGUEL, 2000, p.92).

A adoção de cotas para mulheres candidatas é um exemplo emblemático de ação afirmativa no campo do feminismo e é também uma das experiências mais interessantes da democracia brasileira, visto que

“(...) as cotas eleitorais implicam o questionamento de algumas das premissas básicas do ordenamento político liberal: o indivíduo como única unidade política legítima e o relativo isolamento da arena política (caracterizada pela igualdade formal entre os cidadãos) em relação às injustiças sociais" (MIGUEL, 2000, p.91; grifo da autora).

Tal política é mais do que a reivindicação pelo direito ao reconhecimento das diferenças culturais; é, acima de tudo, uma reivindicação pelo direito ao reconhecimento das desigualdades sociais, demandando assim a adoção de ações estatais de enfrentamento das mesmas. Assim o feminismo denuncia o apagamento das diferenças pretendido pela democracia liberal, bem como sua neutralidade em relação às desigualdades, as quais são remetidas às esferas exteriores ao Estado.

Sérgio Costa e Denílson Werle, recuperando a concepção de Taylor, afirmam:

“(...) ao excluir da esfera pública a luta pelo reconhecimento, o princípio da neutralidade liberal é insuficiente ou inadequado para fornecer critérios que possam mostrar quais reivindicações e formas de reconhecimento das diferenças devem ser consideradas legítimas, justificáveis ou razoáveis pelo Estado" (COSTA; WERLE, 2000, p.216).

Além das cotas para mulheres candidatas, outras ações podem ser citadas como exemplos de incorporação nas políticas públicas de demandas pela incorporação de gênero, tais como a recomendação do Ministério da Saúde para adoção de protocolos especiais no atendimento na rede de saúde à mulher vítima de violência; e a recomendação do Ministério de Planejamento para adoção de critéri- 
os de elegibilidade nos programas habitacionais que facilitem a inserção das mulheres chefes de família.

Quando exige do Estado o atendimento às questões específicas da mulher, o movimento feminista (ou parte dele) põe em xeque alguns pilares da democracia liberal: o indivíduo como "unidade política"; a "universalidade das regras"; a "neutralidade do Estado" e a eleição do mercado como espaço para a satisfação das necessidades da sociedade.

No bojo das reivindicações feministas, a unidade política passa a ser os grupos sociais, nesse caso divididos por sexo. A universalidade das regras é substituída por direitos especiais a grupos específicos. A neutralidade do Estado e das instituições políticas é substituída pela concepção de que o Estado sendo uma arena privilegiada de disputa de poder e representando a condensação das forças políticas presentes na sociedade deve, então, absorver demandas sociais e políticas pela superação das desigualdades econômicas, sociais e culturais. Essa concepção vai na contramão da perspectiva liberal que vê o mercado como o mecanismo de acesso ao direitos liberais e de satisfação das necessidades geradas socialmente. Com isso, as feministas visam a dar legitimidade ao Estado em contraposição ao mercado.

Essas concepções levam as feministas a reivindicar ações estatais para a promoção da eqüidade entre homens e mulheres, bem como entre outros grupos em desvantagens sociais, econômicas e culturais. Rompem com a imagem do Estado neutro e defendem que este é uma arena de forças políticas que traduz e legitima conflitos existentes no seio da sociedade. Nesses termos o Estado adquire centralidade como fórum de disputa por legitimidade social e política, rejeitando a concepção liberal de que tais questões sejam destinadas às esferas societárias e silenciadas no âmbito estatal. Com isso o próprio eixo da democracia é deslocado, em alguns aspectos, da teoria liberal.

Conforme Forst, a neutralidade liberal pode ser interpretada sob três perspectivas. Uma primeira que se refere à "neutralidade das consequiências", em que as "regras estabelecidas deveriam ter as mesmas consequiências para todas as comunidades que compartilham um mesmo sistema político". Uma segunda perspectiva que se refere à "neutralidade dos objetivos" na qual "o Estado liberal não defende qualquer concepção do bem em detrimento de outras concepções”. E uma 
terceira que se refere à "neutralidade da justificação" segundo a qual os "princípios de justiça não podem ser fundados em valores éticos substantivos, mas em conceitos morais universalmente aceitos, portanto, imparciais" (FORST, 1993, apud COSTA; WERLE, 2000, p.212). Pode-se dizer que a concepção e as reivindicações feministas questionam todas essas perspectivas de neutralidade liberal.

Quanto à crítica à universalidade dos direitos, a reivindicação feminista busca "uma forma de igualdade sem mesmidade, compatível com a afirmação da diferença original da humanidade entre masculino e feminino" (SANTOS, 1995, p.240). Essa reivindicação se assenta num princípio de igualdade e diferença, assim formulado por Boaventura de Souza Santos:

"As pessoas e os grupos sociais têm o direito a ser iguais quando a diferença os inferioriza, e o direito a ser diferentes quando a igualdade os descaracteriza" (SANTOS, 1997 apud SCHERERWARREN, 2000, p.34).

Reivindicações por reconhecimento das diferenças compõem o cenário contemporâneo multiculturalista de luta por interesses de extração identitária, ora em defesa da diferença, ora em combate à desigualdade. Nesse cenário o feminismo é visto como o precursor na defesa do direito à diferença. Essas questões colocam a democracia diante de um contexto ao mesmo tempo complexo e contraditório:

"Por um lado, mais do que nunca, se generaliza um consenso ao redor da democracia como um valor universal a ser defendido e garantido, por outro, seu modelo democrático liberal, de certa forma parte das grandes narrativas, tem sido constantemente posto em xeque pelos novos agentes sociais e políticos, que emergem nestas décadas. Se a democracia é reconhecida como um valor; seus princípios universalizantes passam a funcionar como um entrave à incorporação de novos direitos, de culturas diferenciadas, de necessidades alternativas. (...) O debate sobre estas questões na teoria social tem tido grande centralidade no mundo anglosaxônico, derivado da presença dos movimentos sociais, principalmente o feminista e o negro" (PINTO, 2000, p. 136-38).

Admitindo a importância do Estado como poder político, Costa e Werle definem o multiculturalismo como 
“(...) a expressão da afirmação e da luta pelo reconhecimento desta pluralidade de valores e diversidade cultural no arcabouço institucional do Estado democrático de direito, mediante o reconhecimento dos direitos básicos dos indivíduos enquanto seres humanos e o reconhecimento das 'necessidades particulares' dos indivíduos enquanto membros dos grupos culturais específicos" (COSTA; WERLE, 2000, p.208).

Para Nancy Fraser (apud PINTO, 2000), a aparente ambigüidade entre a defesa da igualdade e a defesa da diferença é resolvida pela articulação entre a luta pela eliminação das desigualdades sociais e econômicas (busca da igualdade) e a luta pelo reconhecimento das especificidades culturais (busca da diferença). Assim, a questão do reconhecimento multicultural não pode substituir a luta e a busca do fim da injustiça social e econômica, implicando, então, conciliar a luta por distribuição com a luta por reconhecimento. Nesses termos, a luta contra a desigualdade econômica aponta para o igualitarismo, enquanto a luta por reconhecimento denuncia um tipo de injustiça cultural e simbólica que, para ser superada, deve incluir as diferenças.

Dentro do que se tem habituado chamar de teoria política feminista, Fraser propõe uma transformação estrutural da esfera pública, para dar conta das exclusões e injustiças. Tal proposta está pautada por sua crítica aos princípios sobre os quais se organiza o modelo liberal da esfera pública. Duas questões norteiam sua crítica. Primeiro, entende que a construção da esfera pública se deu sobre exclusões, constituindo-se como branca, burguesa e masculina. Segundo, entende que a esfera pública, quando inclui os sujeitos, coloca as diferenças entre parênteses e, tratando todos como se fossem iguais, discrimina os menos poderosos e os diferentes (FRASER apud PINTO, 2000).

No que se refere ao atendimento das questões de gênero, seja por distribuição, seja por reconhecimento, há uma dimensão de demandas que implica investimentos públicos, como é o caso da área de saúde e de habitação (conforme exemplos já citados), ou ainda de políticas de bens coletivos que aliviem as tarefas socialmente destinadas às mulheres, como creches, por exemplo.

Nesse caso o dilema que se coloca é quanto à pertinência de tais demandas num contexto de crise do Estado em face da globalização 
econômica. Cremos que José María Gómez nos dá as melhores pistas para ainda se manter o Estado como alvo de reivindicações dos movimentos sociais em geral e do feminista em particular, segundo o que interessa nesta discussão. Partimos, então, do entendimento de que

“(...) hoje, mesmo debilitado em quase todos os países nas suas funções de regulação econômica e integração social e criticado como princípio exclusivo de identidade nacional, o Estado continua a ser - e tudo indica que continuará por bastante tempo, não obstante a existência de 'quase' Estados de implantação inacabada ou recente - uma potência política, jurídica, material e simbólica, tenaz e ainda insubstituível. (...) Em suma, contra alguns dos mitos mais difundidos da globalização econômica, os Estados nacionais não estão condenados a desaparecer ou a perder importância, nem muito menos a cessar de promover prioridades estratégicas e medidas específicas tendo em vista favorecer interesses gerais e particulares" (GÓMEZ, 2000, p.107-108).

Contudo, a penetração do movimento de mulheres no Estado e a participação de feministas nos governos não se deram sem conflitos no interior do próprio movimento. Esse novo cenário implicava a institucionalização do movimento de mulheres, o que, para muitas feministas, representava riscos para sua autonomia política. Para o movimento de mulheres, a noção de autonomia havia adquirido contornos cruciais para a busca de uma "nova política". Dessa forma, a escolha entre institucionalizar-se ou manter-se independente da relação com o Estado e as instituições adquiriu grande centralidade nos debates feministas (PAOLI, 1995).

As mudanças que ocorreram na relação entre movimentos sociais e Estado e, em especial, as contribuições do movimento de mulheres para uma nova forma de fazer esta articulação demonstram que a opção entre autonomia e institucionalização é uma falsa escolha ou, antes, é um falso problema. Para Maria Célia Paoli (1995) o antagonismo entre as duas questões já é uma situação superada. O desafio agora para os movimentos sociais é de preservar sua autonomia "na" relação com o Estado, e não mais "sem" o Estado.

Nessa mesma direção, muitas feministas têm apontado como objetivo e desafio do movimento de mulheres a luta para dar legitimida- 
de ao Estado. Com isso, visam a reafirmar o papel social e político do Estado, em contraposição à proposta neoliberal de redução das tarefas estatais e transferência de atividades para o mercado (MURARO, 2000; WAINWRIGHT apud SORJ; GOLDENBERG, 2000).

Porém, não se trata de qualquer Estado, mas da busca por um Estado desprivatizado, com mecanismos de participação democrática e com políticas contrárias à concepção neoliberal, entre outras coisas (MURARO, 2000; WAINWRIGHT apud SORJ; GOLDENBERG, 2000, SCHUMAHER; VARGAS, 1994). Isso significa que, para esta vertente, as feministas não estão dispostas a apoiar todo e qualquer governo pelo benefício da participação no Estado. Schumaher e Vargas (1994, p.362) declaram :

“(...) negamos nossa atuação no Estado quando o governo não se mostra aliado às causas feministas e nos recusamos a participar do 'poder pelo poder' ou do 'poder sem poder"'.

A reivindicação, ao Estado, do movimento de mulheres em geral, e das feministas em particular, diz respeito à incorporação de gênero nas políticas públicas. Em suas propostas, essa incorporação porta um conteúdo crítico em relação às estruturas de poder fundadas no gênero e visa à reestruturação de tal poder. Contudo, a incorporação de gênero nas políticas públicas muitas vezes vem acompanhada de mecanismos de subversão do conteúdo feminista (ALVAREZ, 1988; 2000c).

Embora a preocupação com a perspectiva de gênero seja resultado de pressões feministas, sua incorporação nem sempre se inspira no feminismo. Ocorre com freqüência o que Sônia Alvarez chama de "tradução político-cultural da parte do Estado", quando os governos e a burocracia tomam conceitos dos movimentos em geral; e das feministas em particular, e os traduzem para efeitos que nem sempre são aqueles almejados por suas defensoras (ALVAREZ, 2000c).

Em razão desses riscos de tradução, as reivindicações feministas não são, isoladamente, um parâmetro para supor o sucesso das políticas públicas. No campo político essas reivindicações entram em disputa com forças políticas conservadoras. Como resultado dessa disputa pode ocorrer tanto a anulação das demandas feministas, como a cooptação. A cooptação representaria sua incorporação 
com conteúdo ressignificado, eliminando assim o sentido crítico e emancipador (ALVAREZ, 1988; 2000c; BLAY, 1999), e reforçando os papéis tradicionais, com "políticas públicas com perspectiva de gênero que pouco têm a ver com a equiidade e muito menos com o feminismo" (ALVAREZ, 2000c, p. 22).

Uma vez incorporadas algumas demandas por políticas públicas, sua efetividade dependerá da existência de pressões feministas externas ao Estado, porque, mesmo em seu interior, o Estado não é monolítico e abriga diversas fissuras, conflitos e resistências (ALVAREZ, 1988; 2000c; BLAY, 1999).

Contudo, o risco de uma tradução que possa domesticar a radicalidade da categoria gênero pode ocorrer também no interior do próprio movimento de mulheres, até entre algumas correntes do feminismo (GODINHO, 2000). Neste caso, parcelas do movimento de mulheres podem demandar e legitimar ações do Estado que não tenham como finalidade o empoderamento das mulheres e contribuam para a manutenção do status quo, mesmo utilizando como linguagem a "perspectiva de gênero". Como aponta Mary Louise Pratt (apud COSTA: DINIZ, 1999, p.128) quando não orientada por princípios feministas “a perspectiva de gênero abre espaço para algo descritivo e que acaba legitimando o status quo". Por isso, cabe às pesquisas analisar não só o emprego da linguagem, mas sobretudo a tradução político-cultural dos discursos por parte dos atores.

O fato de privilegiar a ação junto ao Estado e a instâncias de poder provocou uma reformulação nas estratégias e formas de organização do movimento feminista. Assim, é parte constituinte deste novo cenário, principalmente a partir de 1990, a crescente criação de ONGs - organizações não-governamentais - que atuam em áreas específicas de interesses das mulheres como saúde reprodutiva, educação e outras e se caracterizam por uma maior institucionalização. O fenômeno que acompanha o desenvolvimento dessas ONGs é a construção de redes feministas também articuladas em torno de áreas temáticas e que se mobilizam através das fronteiras nacionais, operando localmente e globalmente, seguindo a esteira dinâmica da globalização (ALVAREZ, 2000a; 2000b; MOGHADAM, 2000). 
O processo contemporâneo de globalização contribui significativamente para o crescimento das ONGs e redes feministas que, neste novo cenário, assumem um caráter transnacional. A realização de encontros feministas regionais ou mundiais e as Conferências Mundiais promovidas pelas Nações Unidas possibilitaram a proliferação de discursos e agendas feministas, unificando, em muitos casos, as bandeiras do movimento feminista e ampliando o campo de ação e inserção em outras esferas e temáticas como meio ambiente, população, desenvolvimento, direitos humanos, habitação, etc. Dessa forma multiplicam-se os espaços de interferência, reconfigurando o campo do movimento feminista, o que se reflete na eficácia e na legitimidade do movimento internamente nos vários países, entre os quais o Brasil (ALVAREZ, 2000a; 2000b; MOGHADAM, 2000).

As ONGs tornaram-se interlocutoras privilegiadas do Estado e de organizações internacionais para o planejamento e acompanhamento de ações voltadas para o atendimento às reivindicações feministas que visam à equiidade entre os gêneros e o empoderamento das mulheres. As redes constituídas por essas ONGs contribuem ainda para a mobilização de apoios a propostas de interesses das mulheres (ALVAREZ, 2000a). No caso brasileiro isso ocorre especialmente no que tange à atuação parlamentar, organizando com as redes feministas lobbies com congressistas e com entidades do movimento de mulheres ou de apoio a este, quando da votação de matérias relacionadas ao interesse das mulheres.

Muitas avaliações apontam avanços importantíssimos resultantes da atuação dessas ONGs. Entretanto, o risco que se tem identificado é a possibilidade de este tipo de ação vir a reforçar as tentativas de implantação do neoliberalismo em defesa do Estado mínimo no que diz respeito às funções sociais. Nesse aspecto seriam eliminadas as tensões entre feminismo e liberalismo. Esse risco se materializaria quando as ONGs passam a ser prestadoras de serviços ao Estado, recebendo financiamentos ou firmando contratos de gestão que substituem as funções estatais. Estas ainda são questões que merecem ser mais bem investigadas. Contudo, muitas ONGs e redes feministas ainda se conservam na área de proposição de políticas e de formação de lobbies, mantendo-se assim em debate com o liberalismo. 


\section{Considerações finais}

A trajetória do movimento feminista tal como tratada neste artigo não representa o feminismo como um todo. Muitas vertentes ainda podem ser identificadas dentro deste mesmo movimento, e algumas delas, embora minoritárias, parecem ainda defender a postura de isolamento em relação ao Estado, o que é reflexo de suas dúvidas quanto à própria eficácia do Estado para implantar políticas de cunho feminista, em virtude de sua estrutura ao mesmo tempo engessada e fragmentada.

A participação e/ou representação no Estado é ainda um tema controverso para algumas vertentes do feminismo. Da mesma forma, é também um campo fecundo de estudo para as ciências sociais. Os inúmeros estudos já realizados apontam avanços e dilemas nesta nova forma de relação com o Estado. O principal interesse aqui foi apresentar o debate entre as feministas e a teoria política liberal.

Pode-se dizer que o feminismo foi o precursor (ou pelo menos um deles) de um movimento político que defende o direito à diferença, ao mesmo tempo que defende o direito a determinadas igualdades. $\mathrm{O}$ direito à diferença é o germe de uma nova concepção política que se coloca em debate com alguns dos princípios da teoria política liberal. Este debate, promovido principalmente pelas feministas e pelo movimento negro, tem contribuído para assentar novos parâmetros para a democracia ocidental, o que tem levado as/os ativistas a falarem em ressignificação da democracia e da cidadania, buscando com isso novas formas de distribuição e de reconhecimento.

A democracia e a cidadania visadas por muitos movimentos sociais, e pelas feministas em particular, introduzem alguns princípios políticos e filosóficos que são incompatíveis com alguns outros princípios liberais. Isso tem atribuído uma nova qualidade à democracia e um novo papel ao Estado. Portanto, o Estado é o locus por excelência do debate entre feministas e liberais.

A luta para dar legitimidade ao Estado tem-se configurado em pelo menos dois campos: o enfrentamento às políticas neoliberais e a vigilância à cooptação da categoria "gênero". No primeiro caso, o movimento feminista, como movimento social, é a principal arma de pressão sobre os governos para implantação de políticas sociais estatais. 
No segundo caso, as ONGs feministas têm apresentado importante atuação com o objetivo de dar subsídios técnicos aos governos na incorporação de gênero nas políticas públicas e oferecer vigilância contra as possíveis traduções conservadoras. Entretanto, isso não representa uma rígida divisão de tarefas entre movimento e ONG.

\section{Referências Bibliográficas}

ALVAREZ. Sonia: DAGNINO, Evelina; ESCOBAR, Arturo. Cultura e política nos movimentos sociais latino-americanos: novas leituras. Belo Horizonte: Ed. UFMG, 2000.

ALVAREZ, Sônia E. Politizando as relações de gênero e engendrando a democracia. In: STEPAN. Alfred (Org.). Democratizando o Brasil. Rio de Janeiro: Paz e Terra, 1988. P.315-380.

A "Globalização" dos feminismos latino-americanos: tendências dos anos 90 e desafios para o novo milênio. In: ALVAREZ, Sonia; DAGNINO, Evelina: ESCOBAR, Arturo. Cultura e política nos movimentos sociais latinoamericanos: novas leituras. Belo Horizonte: Ed. UFMG, 2000a.

Translating the global: effects of transnational organizing on local feminist discourses and pratices in Latin America. Paper, 2000b.

Em que Estado está o feminismo latino-americano? Uma leitura crítica das políticas públicas com "perspectiva de gênero". In: FARIA, Nalu, SILVEIRA. Maria Lúcia; NOBRE, Miriam (Orgs.). Gênero nas políticas públicas: impasses. desafios e perspectivas para a ação feminista. São Paulo: SOF, 2000c. p.9-25. (Coleção Cadernos Sempreviva).

BLAY. Eva Alterman. Gênero e políticas públicas ou sociedade civil, gênero e relações de poder. In: SILVA, Alcione Leite da; LAGO, Mara Coelho de Souza; RAMOS. Tânia Regina Oliveira (Orgs.). Falas de gênero: teorias, análises, leituras. Florianópolis: Editora Mulheres, 1999. p.133-146.

BUTTAFUOCO, Annarita. Entre cidadania política e cidadania social. Projetos e experiências do movimento político das mulheres na Itália liberal. In: BONACCI, G.: GROPPI. A. (Orgs.). O dilema da cidadania: direitos e deveres das mulheres. São Paulo: Ed. Unesp, 1995. p.129-158.

COSTA. Claudia de Lima: DINIZ, Alai Garcia. Entrevista: Mary Louise Pratt. Revista Estudos Feministas, Florianópolis, v.7, n.1-2, p.127-140,1999. 
COSTA, Delaine Martins (Coord.). Democratização dos poderes municipais e a questão de gênero. Rio de Janeiro: IBAM/Fundação Ford. 1997.

COSTA, Sérgio. Esfera pública, redescoberta da sociedade civil e movimentos sociais no Brasil: uma abordagem tentativa. Novos Estudos CEBRAP, São Paulo, n. 38. p. 38-52, mar. 1994.

COSTA, Sérgio; WERLE, Denilson Luís. Reconhecer as diferenças: liberais. comunitaristas e as relações raciais no Brasil: In: AVRITZER. Leonardo: DOMINGUES, José Maurício (Orgs). Teoria social e modernidade no Brasil. Belo Horizonte: Ed. UFMG, 2000.

GODINHO, Tatau. A ação feminista diante do Estado: as mulheres e a elaboração de políticas públicas. In: FARIA, Nalu; SILVEIRA, Maria Lúcia: NOBRE. Miriam (Orgs.). Gênero nas políticas públicas: impasses, desafios e perspectivas para a ação feminista. São Paulo: SOF, 2000c. p.26-37. (Coleção Cadernos Sempreviva).

GÓMEZ, José María. Política e democracia em tempos de globalização. Petrópolis: Vozes; Buenos Aires: Clacso, 2000. Cap.2, p.87-139.

JELIN, Elizabeth. Mulheres e Direitos Humanos. Revista Estudos Feministas. Rio de Janeiro, v.2, n.1, p.117-49, 1994.

MIGUEL, Luís Felipe. Teoria Política Feminista e Liberalismo: o caso das cotas de representação. Revista Brasileira de Ciências Sociais, v.15, n.44, p.91-102. out.. 2000.

MOGHADAM, Valentine M. Transnational feminist networks: colletive action in an era of globalization. International Sociology, v.15, n.1, p.57-85. Mar. 2000.

MURARO, Rose Marie. O que querem as mulheres do século 21. Folha de São Paulo. 29 dez. 2000. C.A, p.3.

PAOLI, Maria Célia. Movimentos sociais no Brasil: em busca de um estatuto político. In: HELLMANN, Michaela (Org.). Movimentos sociais e democracia no Brasil: "sem a gente não tem jeito". São Paulo: Marco Zero. 1995. p.2t-55.

PINTO, Céli Regina Jardim. Mulher e Política no Brasil: os impasses do feminismo. enquanto movimento social, face às regras do jogo da democracia representativa. Revista Estudos Feministas, Rio de Janeiro, número especial, p.257-270, 1994.

A democracia desafiada: a presença de direitos multiculturais. In: AVRITZER, Leonardo; DOMINGUES, José Maurício (Orgs). Teoria social e modernidade no Brasil. Belo Horizonte: Ed. UFMG, 2000.

SANTOS, Boaventura de Souza. Subjetividade, cidadania e emancipação. In: Pela mão de Alice: O social e o político na Pós-Modernidade. São Paulo: Cortez. 1995. p.235-280. 
SCHERER-WARREN, Ilse. Movimentos em cena... e as teorias por onde andam? In: SCHEKER-WARREN Iies LEIS, Hector COSTA Sérglo: et al cidadana e Multiculturalismo, a teoria social no Buasil contemporâneo Lisbon. Socius. 2000. p. $2.3-51$.

SCHUMAHER, Maria Aparecida: VARGAS. Elisabeth. Lugar no governo: álibi on conguistrt Revist Estudos Feninistas. Rio de Janeiro, 1.2, n.3, p.l1749. 1994.

SORJ, Bila: GOLDENBERG. Mirian. Entrevista: Hilary Wainwright. Reyista Estudos Femmistas Forínópolis. V.8, h.1, p.115- $126,2000$.

\section{Abstract}

This articte deals with the development of the feminist movement in Brazil focusing on its cthinge of defintion of State. as well as its conflicts with the principles of liberal dentociny. The central focts of discussion is the contribution of the feminist demands. since they bring into debate the limutations of liberal democratic regines. thus creating new denocratic principles. Such leorganization is discussed upon fenumist dennads for public policies concerning gender issues, especially affimative actions sccking to compensate for the disadvantages experienced by wonnen.

Key-words: Feminism: Gender: Public Policies: Democracy. 